\title{
O QUE EXPLICA A PROPENSÃO AO ENDIVIDAMENTO DOS JOGADORES PROFISSIONAIS DE FUTEBOL?
}

\section{WHAT EXPLAINS THE PROPERTY TO THE DEBT OF PROFESSIONAL SOCCER PLAYERS?}

\section{RESUMO}

Este estudo objetiva verificar os fatores explicativos para a propensão ao endividamento de jogadores profissionais de futebol. Os dados são provenientes de questionários aplicados a 45 jogadores profissionais de futebol, os quais foram analisados por meio da análise fatorial e da regressão quantílica. Os resultados revelam que o exercício do poder e prestígio aumenta a propensão ao endividamento dos respondentes que têm baixa e baixíssima propensão a se endividar e que jogadores ansiosos possuem relação com a propensão ao endividamento elevado. Constatou-se ainda que a atitude com cartão de crédito está positivamente relacionada com a pouca propensão ao endividamento. As implicações teóricas versam em discutir fatores que são explicativos para a propensão ao endividamento a partir da ótica de um público específico, os jogadores de futebol. No campo prático, demonstra-se que a sensação do poder e prestígio pode ser preditor para o endividamento e que alguns jogadores gozam desta posição. Isso requer equilíbrio e consciência para não gastar em excesso. Deve-se, também, atentar para a ansiedade, uma vez que esta pode conduzir ao endividamento. Alerta-se para a necessidade de gestão das finanças ao longo da carreira ao saber que a atividade finda em período curto, o que este profissional deve pensar de forma contínua no seu pós-carreira.

Palavras-chave: Propensão ao endividamento. Planejamento Financeiro. Jogadores profissionais de futebol.

\begin{abstract}
The objective of this study went verify the explanatory factors for the propensity to borrow from professional soccer players. The data come from a questionnaire applied to 45 professional soccer players, which analyzed through factorial analysis and quantile regression. The results show that the exercise of power and prestige increases the propensity to the indebtedness of the respondents who has low and very low propensity to be indebted and that anxious players related to the propensity to very high indebtedness. It also verified that the attitude with credit card positively related to the low propensity to indebtedness. The theoretical implications are to discuss factors that are explanatory of players' propensity for indebtedness. In the practical field, it shown that the sense of power and prestige can be a predictor of indebtedness and that some players enjoy this position. This requires balance and awareness not to overspend. One must also pay attention to anxiety once it leads to indebtedness. It alerted the need of management of the finances throughout the race to know that the activity ends in a short period, what this professional must think of continuous form in its post-race.
\end{abstract}

Keywords: Propensity to indebtedness. Financial planning. Professional soccer players.
Thiago Bruno de Jesus Silva Doutorando em Contabilidade pela Universidade Federal de Santa Catarina (UFSC), Mestre em Ciências Contábeis (2016) pela Universidade Regional de Blumenau (FURB), Especialista em Controladoria (2013) e Bacharel em Ciências Contábeis (2012) pela Universidade do Estado da Bahia (UNEB). Professor da Universidade Federal da Grande Dourados (UFGD) do Curso de Ciências Contábeis. E-mail: thiagobsilva@ufgd.edu. br. Telefone: 067-3410-2057. Mais informações: Lattes:http://lattes. cnpq.br/5058637547449065. Blog: thiagobrunoblog.wordpress.com

\section{Allison Manoel de Sousa}

Doutorando em Contabilidade pela Universidade Federal do Paraná (UFPR), Mestre em Contabilidade (2020) pela Universidade Federal de Santa Catarina (UFSC) e Bacharel em Ciências Contábeis (2018) pela Universidade Federal da Grande Dourados (UFGD). E-mail: allison.msousa@gmail.com. Telefone: (67) 98136-4675. Mais informações: Lattes: http://lattes.cnpq br/5391186543607099

\section{Rodrigo Rengel}

Doutorando em Contabilidade pela Universidade Federal de Santa Catarina (UFSC), Mestre em Ciências Contábeis (2020) pela Universidade Federal de Santa Catarina (UFSC) e Bacharel em Ciências Contábeis (2018) pela Universidade do Estado de Santa Catarina (UDESC)

E-mail: rengel.rodrigo@hotmail.com. Telefone: (47) 99995-0252. Mais informações: Lattes - http://lattes.cnpq $\mathrm{br} / 7659927470050481$ 


\section{INTRODUÇÃO}

A aposentadoria do esporte profissional é uma realidade inevitável que todos os atletas enfrentarão (Lavalle, 2005). Isso requer que um atleta profissional se ajuste a um ambiente que é diferente do qual está acostumado (Surujlal, 2016). Logo, são obrigados a planejar sua aposentadoria do esporte ainda jovens, visto que sua carreira no esporte profissional é curta. Em alguns casos, os períodos de carreira dos atletas profissionais podem ser encurtados ainda mais devido a fatores como lesões (Vickers, 2014). Nesta esteira, esta investigação enfoca os jogadores profissionais de futebol, haja vista as peculiaridades destes profissionais quanto à carreira.

Os lucrativos salários, patrocínios e endossos resultam em jovens que consideram o futebol como a primeira escolha da carreira (Surujlal, 2016). Em contraste com outras carreiras, como médica, jurídica e empresarial, que exigem normalmente pré-requisitos educacionais, o principal critério exigido para entrar no futebol profissional é o talento individual (Maseko \& Surujlal, 2011). Em sua decorrência, aspirantes a jogador profissional de futebol saem cedo da escola e de casa para avançar na carreira (Bourke, 2003). Desta forma, possuem pouca educação formal e habilidades financeiras incipientes para o planejamento financeiro (Surujlal, 2016).

Referidos profissionais recebem salários lucrativos com pouca compreensão de como administrar suas finanças (Ramsey, 2010). De forma consequente, utilizam sua renda de forma excessiva, sobretudo, nos seus primeiros ganhos, o que os conduz à propensão ao endividamento. No entanto, muitos não conseguem orçar e/ou economizar dinheiro, o que compromete seu futuro, uma vez que isso poderia melhorar seu estilo de vida no futuro (Maseko \& Surujlal, 2013). Nestas circunstâncias, este estudo discute a propensão ao endividamento no âmbito dos jogadores profissionais de futebol.

O endividamento é entendido como o "saldo devedor de um agregado familiar" (Frade et al., 2003, p. 17). Deste modo, os indivíduos possuem emoções, atitude e outros aspectos subjetivos que podem influenciar a propensão ao endividamento (Ferreira, 2013). Para Richers (1984), o comportamento do indivíduo, em seu papel de consumidor, é constituído por práticas emocionais e mentais que são selecionadas na aquisição e uso de produtos e/ou serviços com a finalidade de satisfazer desejos e necessidades. Em virtude disto, os indivíduos consomem mais do que podem pagar, surgindo então a conduta do endividamento (Brown, Taylor \& Price, 2005).

Contudo, pouco se conhece a respeito da propensão ao endividamento de jogadores profissionais de futebol. Visto o contexto e dada a importância do planejamento financeiro para a vida presente e futura do profissional do futebol, delineou-se o seguinte problema de pesquisa: quais os fatores explicativos para a propensão ao endividamento de jogadores profissionais de futebol? Assim, este estudo objetiva verificar os fatores explicativos para a propensão ao endividamento de jogadores profissionais de futebol.

Neste interim, a investigação abordou variáveis estabelecidas na literatura que podem explicar a propensão ao endividamento dos jogadores profissionais de futebol. Utilizou-se a atitude frente ao dinheiro, poder e prestígio, sensibilidade a preço, ansiedade e atitude com cartão de crédito como fatores explicativos, conforme sugerido pelas investigações correlatas de Figueira e Pereira (2014), Gamble, Garling e Michaelsen (2019) e Santos et al., (2019).

O estudo possui algumas contribuições, em especial, para a área de finanças pessoais e psicologia econômica quanto aos preditores do endividamento. Isso, pois, os resultados desta investigação sugerem que poder e prestígio, atitude com cartão de crédito e ansiedade explicam a propensão ao endividamento dos jogadores profissionais de futebol. A maioria dos estudos foi realizada com amostras compostas por estudantes, por conseguinte, sabe-se pouco sobre jovens e adultos em outras situações de vida (Lachance, 2012), como é o caso desta investigação.

Contribui-se, também, para a literatura da pesquisa referente à atitude frente ao dinheiro (poder e prestígio, sensibilidade ao preço e ansiedade) ao abordar um público específico, conforme sugerido por Figueira e Pereira (2014) e Gamble, Garling e Michaelsen (2019) e Santos et al., (2019). Os resultados apontam que o exercício do poder e do prestígio aumentam a propensão ao endividamento dos respondentes que têm baixa e baixíssima propensão a se endividar. E que jogadores ansiosos possuem relação com a propensão ao endividamento elevadíssima. Ressalta-se, ainda, que esta investigação, também, contribui com a literatura sobre a atitude com cartão de crédito. Isto, porque, constatou-se que a atitude com cartão de crédito aumenta a propensão ao endividamento dos jogadores profissionais de futebol que apresentam baixa propensão a se endividar.

No campo prático, os resultados sugerem que a sensação de poder e prestígio pode ser preditora para o endividamento e que alguns jogadores gozam desta posição. Isso requer equilíbrio e consciência para não gastar em excesso. Deve-se, também, atentar-se para a ansiedade, uma vez que esta conduz ao endividamento. Alerta-se para a necessidade de gestão das finanças ao longo da carreira do futebol ao saber que a atividade finda em período curto, e que o profissional deve pensar de forma contínua no seu pós-carreira. Deste modo, a contabilidade serve como ferramenta de auxílio no controle e no processo decisório, seja de organizações ou de indivíduos. Recomenda-se aos jogadores que procurem os serviços de um profissional contábil como consultor financeiro e que busquem um programa intensivo para se educarem sobre orçamento, sobre como administrar um negócio, entre outros. Isso permitirá que planejem uma situação financeira sustentável em sua aposentadoria. 


\section{FUNDAMENTAÇÃO TEÓRICA E HIPÓTESES}

Diferente da concepção e divulgação nacional, a realidade financeira de jogadores de futebol é extremamente heterogênea (Damo, 2005). Dados da Confederação Brasileira de Futebol (CBF) apontam que a realidade vivida por jogadores profissionais em sua grande parte está distante dos milhões, holofotes, glamour, mansões e carros de luxo. Mais de $80 \%$ dos jogadores profissionais do futebol brasileiro recebem salário de até R $\$ 1$ mil por mês, destaca-se ainda que $96 \%$ ganham até $\mathrm{R} \$ 5$ mil por mês (CBF, 2016).

Além das preocupações durante a carreira profissional, os jogadores de futebol devem se alertar para suas aposentadorias, já que esta é uma atividade com "prazo de validade”, uma vez que a carreira é curta (Brandão, 2001, Amaral, Thiengo \& Oliveira, 2007; Aroni et al., 2019, por exemplo). Em virtude desta aposentadoria precoce, é necessário conhecimento para administrar suas finanças (Moraes, 1981).

Maseko e Surujlal (2013) concluíram que o planejamento financeiro entre os jogadores profissionais constitui campo de estudo dinâmico e complexo. Para o autor, os jogadores de sua amostra (da África do Sul) são despreparados para o momento após o término de sua carreira. Esses devem buscar auxílio com serviços de conselheiros em quem podem confiar e os clubes de futebol devem oferecer educação financeira. A intenção é que os jogadores profissionais entendam a importância do planejamento financeiro e se tornem responsáveis por sua própria segurança financeira (Maseko \& Surujlal, 2013).

Para Surujlal (2016) o departamento de gestão de recursos humanos da organização esportiva, deve auxiliar os jogadores profissionais de futebol em seu planejamento financeiro, visando suas aposentadorias. Em muitos casos, estes são recrutados jovens e tem suas habilidades desenvolvidas no esporte. Assim, não possuem educação formal e habilidades financeiras para planejar sua aposentadoria (Surujlal, 2016).

Nesta esteira, Agresta, Brandão e Barros Neto (2008) relatam que grande parte dos ex-jogadores profissionais piora sua situação econômica após a aposentadoria. Aroni et al. (2019) concluíram que nenhum jogador (de sua amostra) possui planejamento financeiro. De forma particular, a partir das discussões acima este estudo tem o propósito de investigar os antecedentes do endividamento relacionados aos jogadores profissionais de futebol. Isto, porque, entende-se que o endividamento é antecedente e pode comprometer o planejamento financeiro dos jogadores profissionais de futebol.

Ferreira (2006) apresenta que endividamento significa fazer/contrair dívidas. Embora seja associada a algo negativo, ressalta-se que este pode ser visto como uma estratégia de crescimento econômico, como ao financiar um imóvel (Marques et al., 2000). A falta de controle leva à inadimplência, causada por parcelas superiores as disponibilidades do indivíduo, ou seja, a incapacidade de quitar as dívidas contraídas (Ferreira, 2006; Keese, 2012). O contexto econômico elevou significativamente o endividamento dos últimos anos (CNC, 2016; SPC, 2016), assim, deve-se encarar com cautela o comprometimento da renda.

O Sindicato de Jogadores de Futebol da África do Sul (SARFU) relatou alguns dos problemas enfrentados por ex-jogadores sul-africanos de futebol profissionais, tais como o analfabetismo, o endividamento ocasionado pelo planejamento financeiro deficiente e abuso de substâncias (Fleishman-Hillard, 2011). Contudo, estes problemas variam de acordo com a preparação e características individuais (Maseko \& Surujlal, 2013).

No entanto, a situação financeira momentânea e as projeções futuras impactam diretamente na percepção da dívida (Keese, 2012). A partir do dinheiro, é possível a realização de atividades cotidianas, como compras de suprimentos, bens materiais, entre outros (Figueira \& Pereira, 2014). O dinheiro se tornou ferramenta de status e autoestima, utilizado para obtenção da aprovação dos pares (Wang \& Xiao, 2009; Figueira \& Pereira, 2014). E sua falta se tornou ameaça à própria segurança, seja ela física ou psicológica (Yamauchi \& Templer, 1982). Assim, os jogadores profissionais de futebol podem ser conduzidos por percepção de dinheiro de forma que conduza ao endividamento.

A atitude frente ao dinheiro é apresentada em três constructos por Roberts e Jones (2001): (i) poder e prestígio; (ii) sensibilidade a preço; e (iii) ansiedade. A percepção do dinheiro é compreendida como objeto de poder e prestígio, logo, associa-se a aquisições extras, que está diretamente associada ao endividamento (Yamauchi \& Templer, 1982; Tokunaga, 1993; Markovich \& DeVaney, 1997; Norum, 2008; Wang, Lu \& Malhorta, 2011; Wang, Lv \& Jiang, 2011; Figueira \& Pereira, 2014).

A atitude do indivíduo frente ao dinheiro também pode apresentar uma sensibilidade ao preço, como apontado por Roberts e Jones (2001). Isto é, quanto maior a percepção do indivíduo quanto aos preços "normais", maior sua sensibilidade ao preço. Assim, torna-se menos propenso a realização de gastos extras, o que diminui sua propensão ao endividamento (Tokunaga 1993; Norum, 2008; Wang, Lu \& Malhorta, 2011; Figueira \& Pereira, 2014), o que pode apresentar relação negativa ao endividamento.

Por último, Roberts e Jones (2001) apresentam a ansiedade do indivíduo, no qual é ligada diretamente com a propensão de endividamento, por motivar compras compulsivas, impulsivas e gastos extras para sanar tal sentimento pessoal (Eastwood, 1975; Yamauchi \& Templer, 1982; Norum, 2008; Wang \& Xiao, 2009; Figueira \& Pereira, 2014).

Desta forma, este estudo propõe as seguintes hipóteses:

H1 - Poder e prestígio impactam positivamente a propensão ao endividamento dos jogadores profissionais de futebol

H2 - Sensibilidade a preço impacta negativamente a propensão ao endividamento dos jogadores profissionais de futebol

H3 - Ansiedade impacta positivamente à propensão ao endividamento dos jogadores profissionais de futebol

O número de devedores incapazes de pagar suas dívidas é fruto de pesquisas e chama atenção da sociedade. Uma 
das formas de endividamento mais presente no cotidiano é o cartão de crédito. Este se tornou um inimigo financeiro para muitos. O uso deste se tornou motivo de preocupação tanto social quanto econômica (Mansfield \& Pinto, 2008). A atitude do indivíduo frente ao uso do crédito é fundamental na previsão de dívida do cartão de crédito (Wang, Lv, \& Jiang, 2011; Xiao et al., 2011; Figueira \& Pereira, 2014). O fácil acesso ao crédito é um dos causadores dos gastos excessivos (Cheema \& Soman, 2006).

Veludo de Oliveira, Ikeda e Santos (2004) observaram que o aumento de inadimplência dos consumidores ocorreu de forma simultânea à evolução e acesso ao cartão de crédito. Em pesquisa realizada pela Confederação Nacional do Comércio de Bens, Serviços e Turismo (CNC) (2016), 73\% do endividamento da população é ocasionado via cartão de crédito.

Benefícios como a segurança por não movimentar moeda em papel (Erasmus \& Lebani, 2008) e a facilidade de crédito permitem a satisfação dos desejos de compra dos consumidores (Bernthal, Crockett, \& Rose, 2005; Erasmus \& Lebani, 2008) condicionam sua aceitação/utilização. Contudo, sua utilização torna o indivíduo mais propenso a compras adicionais (Feinberg, 1986; Roberts \& Jones, 2001; Cheema \& Soman, 2006; Norum, 2008; Lo \& Harvey, 2011). Destarte, juros incrementais são ocasionados (Bernthal, Crockett, \& Rose, 2005). Outro problema está no fato de que tais dívidas se tornaram socialmente aceitáveis (Wickramasinghe \& Gurugamage, 2009). Indivíduos com atitude positiva frente à dívida são menos propensos a se tornarem endividados (Wang, Lv \& Jiang, 2011; Figueira \& Pereira, 2014). Neste sentido, entende-se que caso os jogadores profissionais de futebol não possuam habilidades financeiras para planejar sua aposentadoria (Surujlal, 2016), estes podem ser propensos ao endividamento pela utilização do cartão de crédito.

Dada as discussões, propõe-se a seguinte hipótese:

H4 - A atitude com cartão de crédito impacta positivamente à propensão ao endividamento dos jogadores profissionais de futebol

Na Figura 1, apresenta-se o modelo teórico do estudo com a elucidação da hipótese.

Figura 1. - Modelo Teórico do estudo

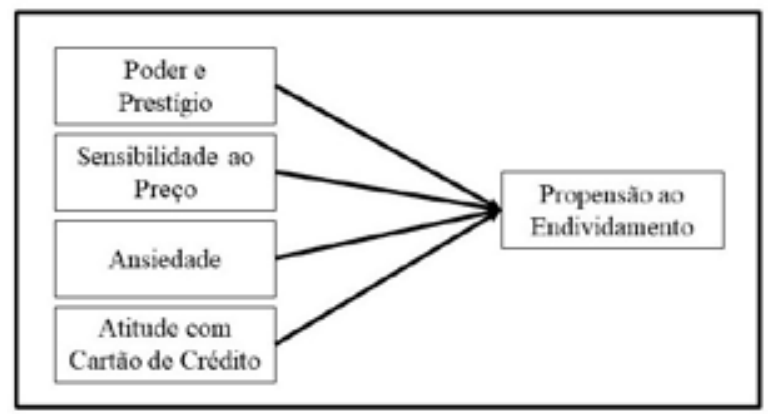

Fonte: Elaborado pelos autores (2019)

Observa-se que o endividamento dos jogadores profissionais de futebol tem relação direta com o poder e prestígio, sensibilidade ao preço, ansiedade e atitude com cartão de crédito.

\section{TRAJETÓRIA METODOLÓGICA}

Para verificar os fatores que explicam o endividamento de jogadores profissionais de futebol, adotou-se uma pesquisa descritiva quanto ao objetivo, de levantamento quanto aos procedimentos e quantitativa quanto ao problema de investigação.

Esta investigação aplicou um questionário em jogadores profissionais de futebol brasileiros que trabalham no Brasil e no exterior. A coleta de dados ocorreu entre os meses de fevereiro de 2018 a abril de 2019 pela plataforma Google Docs. O link foi enviado por meio da rede social Facebook e Instagram. Em ambas, enviou-se mensagem privada aos jogadores no qual explicava a pesquisa e o convidava para participar. Deste modo, a amostra foi não probabilística por acessibilidade, das 45 respostas recebidas.

Na Tabela 1, apresenta-se a caracterização dos respondentes (escolaridade, renda, idade). 
Tabela 1 - Caracterização dos respondentes

\begin{tabular}{|c|c|c|c|c|c|c|c|c|c|c|c|}
\hline \multicolumn{12}{|c|}{ Painel A: Nível de escolaridade dos respondentes } \\
\hline \multirow{2}{*}{$\begin{array}{l}\text { Variável } \\
\text { Num. Jog. }\end{array}$} & & \multicolumn{2}{|c|}{$\begin{array}{l}\text { Até o Ensino } \\
\text { Médio }\end{array}$} & \multicolumn{2}{|c|}{$\begin{array}{l}\text { Superior } \\
\text { Incompleto }\end{array}$} & \multicolumn{2}{|c|}{$\begin{array}{l}\text { Superior } \\
\text { Completo }\end{array}$} & \multicolumn{2}{|c|}{$\begin{array}{l}\text { Pós-Graduação } \\
\text { Completa }\end{array}$} & \multicolumn{2}{|l|}{ Total } \\
\hline & & $\begin{array}{l}\text { Num. } \\
\text { Jog. }\end{array}$ & $\begin{array}{l}\text { Freq. } \\
(\%)\end{array}$ & $\begin{array}{l}\text { Num. } \\
\text { Jog. }\end{array}$ & $\begin{array}{l}\text { Freq. } \\
(\%)\end{array}$ & $\begin{array}{l}\text { Num. } \\
\text { Jog. }\end{array}$ & $\begin{array}{l}\text { Freq. } \\
(\%)\end{array}$ & $\begin{array}{l}\text { Num. } \\
\text { Jog. }\end{array}$ & $\begin{array}{l}\text { Freq. } \\
(\%)\end{array}$ & $\begin{array}{l}\text { Num. } \\
\text { Jog. }\end{array}$ & $\begin{array}{l}\text { Freq. } \\
(\%)\end{array}$ \\
\hline \multicolumn{2}{|l|}{ Escolaridade } & 34 & 76 & 4 & 9 & 6 & 13 & 1 & 2 & 45 & 100 \\
\hline \multicolumn{12}{|c|}{ Painel B: Mediana da Renda dos Jogadores por Divisão em RS } \\
\hline Variável & $\begin{array}{l}\text { Primeira } \\
\text { Divisão }\end{array}$ & \multicolumn{2}{|c|}{ Segunda Divisão } & \multicolumn{2}{|c|}{$\begin{array}{l}\text { Terceira } \\
\text { Divisão }\end{array}$} & \multicolumn{2}{|c|}{ Quarta Divisão } & \multicolumn{2}{|c|}{$\begin{array}{l}\text { Desempregado/ } \\
\text { aposentado }\end{array}$} & \multicolumn{2}{|c|}{$\begin{array}{l}\text { Mediana do } \\
\text { Total }\end{array}$} \\
\hline Renda Familiar & $\mathrm{R} \$ 9.000,00$ & \multicolumn{2}{|c|}{$\mathrm{R} \$ 9.000,00$} & \multicolumn{2}{|c|}{$\mathrm{R} \$ 4.500,00$} & \multicolumn{2}{|c|}{$\mathrm{R} \$ 4.500,00$} & \multicolumn{2}{|c|}{$\mathrm{R} \$ 5.250,00$} & \multicolumn{2}{|c|}{$\mathrm{R} \$ 6.000,00$} \\
\hline
\end{tabular}

Legenda: Num. Jog. = Número de Jogadores; Freq. = Frequência;

Fonte: Dados da pesquisa (2019)

Na Tabela 1, destaca-se que a escolaridade, de forma predominante, foi até o ensino médio com $76 \%$. Em seguida, com $13 \%$, jogadores profissionais que concluíram o ensino superior. A mediana da renda familiar foi de R $\$ 6.000,00$. Jogadores da primeira e segunda divisão possuem renda familiar de $R \$ 9.000,00$. A menor renda familiar foi de $R \$ 1.000,00$ e a maior de $R \$$ $150.000,00$. Adicionalmente, $40 \%$ dos respondentes disputam a primeira divisão, $24 \%$ a segunda divisão. Em contraste, $13 \%$ encontravam-se desempregado ou aposentado. Vale ressaltar que a divisão não é concernente apenas do Brasil.

$\mathrm{O}$ instrumento de pesquisa compõe-se de seis blocos. O primeiro bloco cobre o constructo da Propensão ao endividamento, com 2 questões, construído pelo estudo do Lea e Davies (1995) e testado por Figueira e Pereira (2014), Gamble, Garling e Michaelsen (2019) e Santos et al., (2019). O segundo bloco cobre constructo do Poder e Prestígio, com 5 questões, construído por Yamauchi e Templer (1982) adaptado por Roberts e Jones (2001) e testado por Figueira e Pereira (2014) e Harnish et al., (2018). No terceiro bloco, foram 6 questões sobre Sensibilidade ao Preço criadas por Yamauchi e Templer (1982), adaptado por Roberts e Jones (2001) e testado por Figueira e Pereira (2014) e Harnish et al., (2018). O quarto bloco cobre o constructo de compra ansiedade construído por Roberts e Jones (2001), adaptado por Roberts e Jones (2001) e testado por Figueira e Pereira (2014) e Harnish et al., (2018). O quinto bloco, foram 7 questões sobre atitude com cartão de crédito construído por Roberts e Jones (2001), adaptado por Norum (2008) e testado por Figueira e Pereira (2014). O sexto bloco foi composto por questões de caracterização do respondente. Estes constructos estão descritos na Tabela 2 que apresenta cada variável.

Tabela 2 -Caracterização das variáveis adotadas na investigação, quanto a mensuração e fundamentação teórica.

\begin{tabular}{|c|c|c|}
\hline Variáveis & Mensuração & Fundamentação teórica \\
\hline Propensão ao Endividamento & $\begin{array}{l}\text { Questões (2) Escala Likert } 1 \text { a } 10 \\
\text { (Discordo - Concordo) }\end{array}$ & Lea e Davies (1995) \\
\hline Poder e Prestígio & $\begin{array}{l}\text { Questões (5) Escala Likert } 1 \text { a } 10 \\
\text { (Discordo - Concordo) }\end{array}$ & $\begin{array}{l}\text { Yamauchi e Templer } \\
\text { (1982) }\end{array}$ \\
\hline Sensibilidade ao Preço & $\begin{array}{l}\text { Questões (6) Escala Likert } 1 \text { a } 10 \\
\text { (Discordo - Concordo }\end{array}$ & $\begin{array}{l}\text { Yamauchi e Templer } \\
\text { (1982) }\end{array}$ \\
\hline Ansiedade & $\begin{array}{l}\text { Questões (6) Escala Likert } 1 \text { a } 10 \\
\text { (Discordo - Concordo) }\end{array}$ & $\begin{array}{l}\text { Yamauchi e Templer } \\
\text { (1982)) }\end{array}$ \\
\hline Atitude com Cartão de Crédito & $\begin{array}{l}\text { Questões (7) Escala Likert } 1 \text { a } 10 \\
\text { (Raramente - Sempre) }\end{array}$ & $\begin{array}{l}\text { Yamauchi e Templer } \\
\text { (1982) }\end{array}$ \\
\hline
\end{tabular}

Fonte: Dados da pesquisa (2019)

Os dados foram analisados por meio da análise fatorial e da regressão quantílica. Utilizou-se a análise fatorial (pelo método Varimax) para reduzir o número de variáveis que são altamente correlacionadas entre si, conforme apresenta Hair Junior et al., (1998). Em seguida, a regressão quantílica (com 20 replicações), extensão do modelo clássico de regressão linear (Koenker \& Basset, 1978), foi utilizada com o intuito de determinar as variáveis explicativas com maior capacidade de previsão para a variável dependente. Como variável dependente, a propensão ao endividamento. As variáveis independentes de interesse correspondem ao poder e prestígio, sensibilidade ao preço, ansiedade e atitude 
com cartão de crédito. Adicionalmente, utilizou-se variáveis independentes de controle, de acordo com características demográficas dos respondentes, como a escolaridade (uma vez que esta tem relação com o endividamento, como exposto por Gathergood, 2012, Keese, 2012, Sevim, Temizel e Sayilir, 2012) e renda (por ter reflexo no endividamento como apresentado por Hayhoe et al. 1999 e Diniz et al., 2016).

\section{ANÁLISE E DISCUSSÃO DOS DADOS}

De forma inicial, realizou-se a análise das informações dos respondentes, no que se refere as alternativas escolhidas referente as questões de cada constructo, conforme apresentado na Tabela 3.

Tabela 3 - Estatística descritiva das variáveis

\begin{tabular}{|c|c|c|c|c|c|c|c|c|c|c|c|c|c|}
\hline \multirow{2}{*}{ Constructos } & \multirow{2}{*}{ Questões } & \multirow{2}{*}{ Frequência } & \multicolumn{10}{|c|}{ Respostas } & \multirow{2}{*}{ Total } \\
\hline & & & 1 & 2 & 3 & 4 & 5 & 6 & 7 & 8 & 9 & 10 & \\
\hline \multirow{4}{*}{ Propensão } & \multirow{2}{*}{ Q1 } & $\mathrm{Fi}$ & 22 & 2 & 2 & 6 & 2 & 1 & 1 & 2 & 1 & 6 & 45 \\
\hline & & $\mathrm{Fi} \%$ & 49 & 4 & 4 & 13 & 4 & 2 & 2 & 4 & 2 & 13 & 100 \\
\hline & \multirow{2}{*}{ Q2 } & $\mathrm{Fi}$ & 25 & 3 & 1 & 3 & 7 & 1 & 2 & 0 & 2 & 1 & 45 \\
\hline & & $\mathrm{Fi} \%$ & 56 & 7 & 2 & 7 & 16 & 2 & 4 & 0 & 4 & 2 & 100 \\
\hline \multirow{9}{*}{ Poder } & \multirow{2}{*}{ Q1 } & $\mathrm{Fi}$ & 36 & 2 & 0 & 2 & 3 & 0 & 2 & 0 & 0 & 0 & 45 \\
\hline & & $\mathrm{Fi} \%$ & 80 & 4 & 0 & 4 & 7 & 0 & 4 & 0 & 0 & 0 & 100 \\
\hline & \multirow{2}{*}{ Q2 } & $\mathrm{Fi}$ & 37 & 3 & 0 & 3 & 1 & 0 & 1 & 0 & 0 & 0 & 45 \\
\hline & & $\mathrm{Fi} \%$ & 82 & 7 & 0 & 7 & 2 & 0 & 2 & 0 & 0 & 0 & 100 \\
\hline & \multirow{2}{*}{ Q3 } & $\mathrm{Fi}$ & 32 & 2 & 2 & 1 & 1 & 1 & 1 & 1 & 0 & 4 & 45 \\
\hline & & $\mathrm{Fi} \%$ & 71 & 4 & 4 & 2 & 2 & 2 & 2 & 2 & 0 & 9 & 100 \\
\hline & \multirow{2}{*}{ Q4 } & $\mathrm{Fi}$ & 32 & 2 & 0 & 4 & 2 & 2 & 0 & 2 & 0 & 1 & 45 \\
\hline & & $\mathrm{Fi} \%$ & 71 & 4 & 0 & 9 & 4 & 4 & 0 & 4 & 0 & 2 & 100 \\
\hline & ᄀ & $\mathrm{Fi}$ & 41 & 3 & 0 & 0 & 0 & 1 & 0 & 0 & 0 & 0 & 45 \\
\hline \multirow{11}{*}{ Sensibilidade } & Q & $\mathrm{Fi} \%$ & 91 & 7 & 0 & 0 & 0 & 2 & 0 & 0 & 0 & 0 & 100 \\
\hline & \multirow{2}{*}{ Q1 } & $\mathrm{Fi}$ & 21 & 2 & 4 & 1 & 7 & 3 & 2 & 1 & 0 & 5 & 46 \\
\hline & & $\mathrm{Fi} \%$ & 47 & 4 & 9 & 2 & 16 & 7 & 4 & 2 & 0 & 11 & 102 \\
\hline & \multirow{2}{*}{ Q2 } & $\mathrm{Fi}$ & 15 & 2 & 5 & 5 & 8 & 1 & 1 & 0 & 0 & 8 & 45 \\
\hline & & $\mathrm{Fi} \%$ & 33 & 4 & 11 & 11 & 18 & 2 & 2 & 0 & 0 & 18 & 100 \\
\hline & \multirow{2}{*}{ Q3 } & $\mathrm{Fi}$ & 23 & 2 & 1 & 0 & 6 & 2 & 2 & 3 & 1 & 5 & 45 \\
\hline & & $\mathrm{Fi} \%$ & 51 & 4 & 2 & 0 & 13 & 4 & 4 & 7 & 2 & 11 & 100 \\
\hline & \multirow{2}{*}{ Q4 } & $\mathrm{Fi}$ & 22 & 1 & 5 & 3 & 7 & 1 & 3 & 2 & 0 & 1 & 45 \\
\hline & & $\mathrm{Fi} \%$ & 49 & 2 & 11 & 7 & 16 & 2 & 7 & 4 & 0 & 2 & 100 \\
\hline & \multirow{2}{*}{ Q5 } & $\mathrm{Fi}$ & 9 & 1 & 2 & 3 & 2 & 0 & 1 & 4 & 2 & 21 & 45 \\
\hline & & $\mathrm{Fi} \%$ & 20 & 2 & 4 & 7 & 4 & 0 & 2 & 9 & 4 & 47 & 100 \\
\hline
\end{tabular}




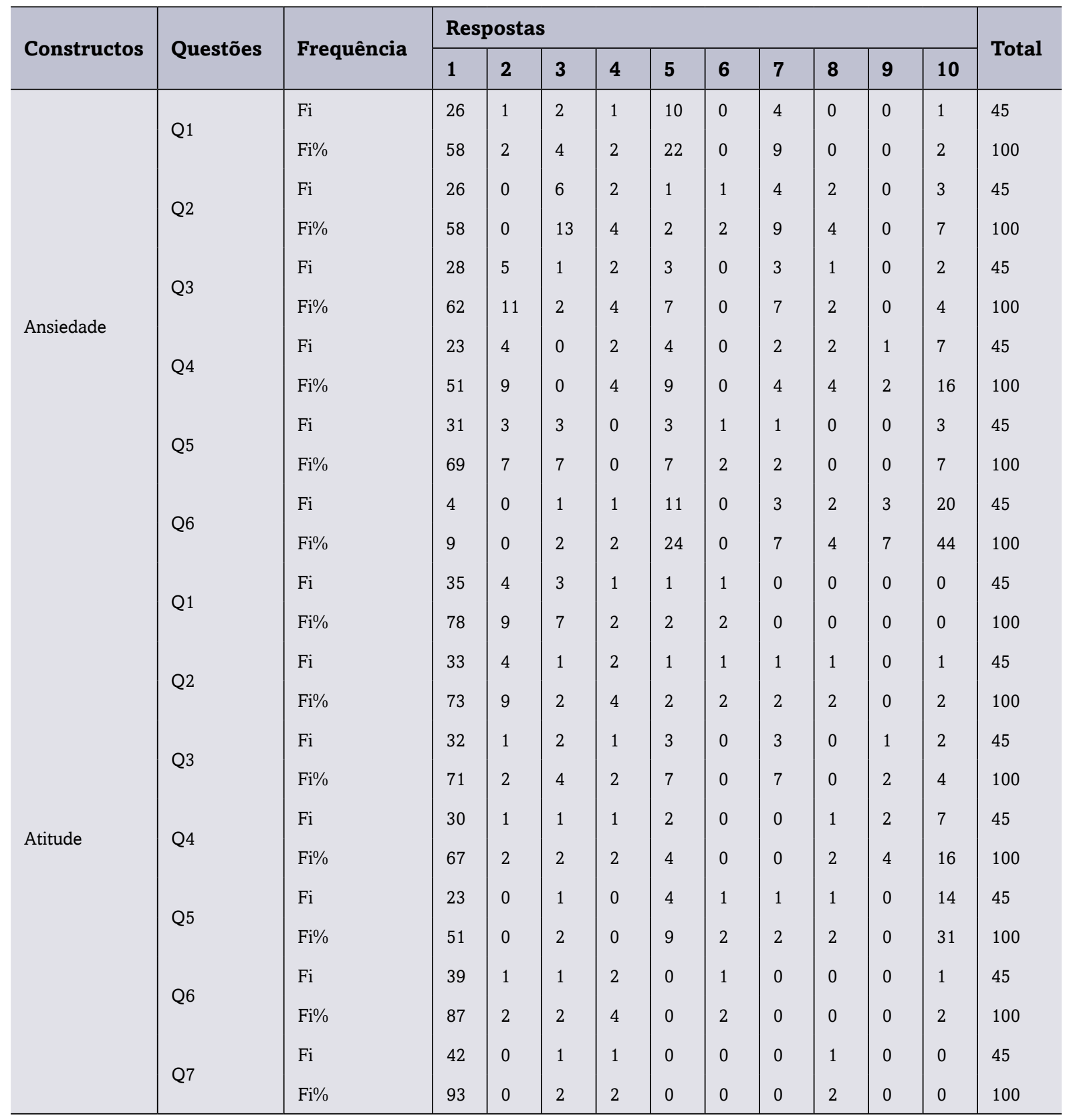

Legenda: Fi = Frequência Absoluta; Fi\%: Frequência Relativa

Fonte: Dados da pesquisa (2019)

Na Questão 1 (Q1) (Prefiro comprar parcelado que esperar ter dinheiro para comprar à vista) do constructo de Propensão ao Endividamento, observa-se que $49 \%$ dos respondentes nunca utilizam modalidades crédito com a finalidade de parcelar a dívida do que comprar à vista. Desta forma, este resultado pode indicar que a maior parte dos respondentes apresentam baixa propensão ao endividamento, uma vez que esperam ter o montante necessário para fazer a aquisição de um novo produto ou serviço. Resultado dissemelhante com a investigação de Figueira e Pereira (2014), uma vez que os autores evidenciaram que os respondentes, em geral, concordaram com a afirmação da Q1. Além disso, este resultado pode contribuir com a discussão de Schor (1998), dado que mesmo com a acesso a formas de parcelamentos, 49\% dos respondentes declaram que nunca utilizam modalidades de crédito que implique no pagamento por meio de parcelas do que uma compra à vista.

Já na Q2 (Prefiro pagar parcelado mesmo que no total seja mais caro) do constructo de Propensão ao Endividamento, percebe-se que $56 \%$ dos respondentes preferem realizar o pagamento via parcelamento, mesmo que o montante seja maior do que uma compra à vista. Evidência que complementa a Q1, em que a maior parte dos respondentes podem apresentar baixa propensão ao endividamento. Evidência que é semelhante ao de Figueira e Pereira 
(2014), haja vista que os pesquisadores destacam que os respondentes, em média, tendem a não adquirir produtos e serviços em compras parceladas.

Quanto ao constructo de Poder e Prestígio, na Q2 (Embora eu deva julgar as pessoas por seus atos, eu sou mais influenciado a julgar pela quantidade de dinheiro que elas têm), constata-se que $82 \%$ dos respondentes nunca julgam os atos das pessoas ao invés do poder aquisitivo. Evidência similar foi encontrada por Figueira e Pereira (2014), na qual os respondentes demonstraram que discordam da afirmação da Q2. Com isto, os achados desta pesquisa podem indicar que a maioria dos respondentes não são influenciados pelo poder de pessoas com alto poder aquisitivo, como (ao considerar o mundo do futebol), os investidores e componentes do alto escalão dos clubes.

Na Q3 (Eu hesito em gastar dinheiro, mesmo quando necessito) do constructo de Sensibilidade ao Preço, demonstra que $51 \%$ dos respondentes tendem a não gastar dinheiro, mesmo quando seja necessário. Isto pode indicar que a maioria destes é sensível ao preço no que se refere a fazer a aquisição de novos bens, produtos e serviços, mesmo quando necessário. Resultado que pode ser complementado ao analisar a Q5 (Eu gasto dinheiro para me sentir melhor) do constructo de Ansiedade, percebe-se que $69 \%$ dos respondentes discordam desta afirmação. Com isto, estes respondentes ser menos propensos ao endividamento, já que a prerrogativa de atitudes com os recursos financeiros realizada de forma inadequada está associada ao sentimento de ansiedade, como explicitado por Yamauchi e Templer (1982) e Robert e Jones (2001).

No constructo de Atitude com Cartão de Crédito, verifica-se que na Q1 (Meus cartões de crédito estão no seu limite máximo de crédito (ou seja, eu uso todo o limite de crédito disponível) 87\% dos respondentes nunca utilizam os cartões de crédito no seu limite. Este achado pode demonstrar que a maioria dos respondentes utilizam o cartão de crédito adequadamente. Evidência que pode complementar as discussões de Pires (1994), Brandão (2001) e Aroni et al. (2019), já que o uso adequado desta modalidade de crédito pode auxiliar na criação de reservas para a aposentadoria, sobretudo, pois, de acordo com os autores, a carreira deste profissional é curta.

Em seguida, os dados referentes as questões de cada constructo foram submetidas a análise fatorial pelo método Varimax. Na Tabela 4, apresenta-se também os quanto parâmetros que avaliam a validade das análises fatoriais ao considerar os testes de Kaiser-Meyer-Olkin (KMO), Esfericidade de Bartlett's. Também, demonstra-se a extração dos autovalores e, por sua vez, dos escores fatoriais, em que foram consideradas as questões com variação acima de 0,50 da variância extraída. Além disso, para validar os fatores que correspondem aos constructos, recorreu-se ao teste Alfa de Cronbach.

Tabela 4 - Análise dos coeficientes de correlação da Análise Fatorial

\begin{tabular}{|c|c|c|c|c|c|c|c|c|c|c|c|}
\hline Dimensão & & $\begin{array}{l}\text { Teste } \\
\text { KIMO }\end{array}$ & $\begin{array}{l}\text { Teste de } \\
\text { Esfericidade } \\
\text { de Bartlett's }\end{array}$ & Q1 & Q2 & Q3 & Q4 & Q5 & Q6 & Q7 & $\begin{array}{l}\text { Alfa de } \\
\text { Cronbach }\end{array}$ \\
\hline Propensão & Fator 1 & 0.50 & 0.000 & 0.93 & 0.93 & & & & & & 0.83 \\
\hline Poder & Fator 1 & 060 & (2000 & 0.61 & 0.87 & 0.67 & 0.56 & 0.84 & & & 0.60 \\
\hline & Fator 2 & & & -0.56 & -0.24 & 0.56 & 0.61 & -0.20 & & & - \\
\hline Sensibilidade & Fator 1 & 0.79 & 0.000 & 0.83 & 0.76 & 0.75 & 0.70 & 0.69 & & & 0.80 \\
\hline Angir & Fator 1 & $0<0$ & (2000 & 0.81 & 0.70 & 0.51 & 0.67 & 0.64 & 0.45 & & 0.70 \\
\hline Ansseuaue & Fator 2 & 0.00 & 0.000 & 0.04 & 0.32 & -0.68 & -0.18 & -0.17 & 0.69 & & - \\
\hline & Fator 1 & & & 0.68 & 0.50 & 0.71 & 0.72 & 0.55 & 0.38 & 0.58 & 0.65 \\
\hline Allude & Fator 2 & 0.00 & 0.000 & 0.14 & -0.53 & -0.46 & -0.26 & 0.19 & 0.75 & 0.50 & - \\
\hline
\end{tabular}

Fonte: Dados da pesquisa (2019).

No teste KMO, verifica-se que todos os constructos (Propensão ao Endividamento, Atitude com Cartão de Crédito, Poder e Prestígio, Sensibilidade ao Preço e Ansiedade) estão adequados a análise fatorial, uma vez que todos foram iguais ou maiores que 0,50. O teste de Esfericidade de Barllet's demonstra que em todas as análises fatoriais apontam que a matriz de correlações não é igual a matriz identidade. Assim, demonstra que em todos os constructos a análise fatorial realizada é adequada.

No constructo da Propensão ao Endividamento, observa-se que foi composto por apenas um fator que confere a Q1 e Q2. Já, ao considerar outros constructos, como Atitude com Cartão de Crédito, Poder e Prestígio e Ansiedade, percebe-se que a análise fatorial resultou em dois fatores, em que o segundo fator (Fator 2), destes constructos, foram descartados haja vista ter apenas uma questão. Assim, para estes constructos, foram considerados com as questões que se referem ao primeiro fator (Fator 1).

Todas as questões do constructo de Sensibilidade ao Preço foram consideradas, uma vez que correspondem ao mesmo fator (Fator 1) e apresentaram variação acima de 0,50. Além disso, todos as dimensões dos constructos que podem ser analisadas (com pelo menos duas questões e com variação acima de 0,50 ) foram submetidas ao teste de Alfa 
de Cronbach. Os resultados demonstraram que todos os fatores que compreendem aos constructos desta pesquisa são válidos, visto que apresentaram resultado superior a 0,60.

A partir da validade confirmada das dimensões analisadas, pôde-se realizar a estatística descritiva dos dados. $\mathrm{Na}$ Tabela 5, apresenta-se os resultados da estatística descritiva dos fatores que compõem os constructos. Destaca-se que se utilizaram variáveis de controle Renda e Escolaridade para ponderar as discussões promovidas por Maseko (2013) quanto a variação do endividamento de acordo a característica pessoal dos jogadores profissionais.

Tabela 5 - Estatística descritiva

\begin{tabular}{|l|l|l|l|l|l|l|l|}
\hline Variáveis & P25 & Mediana & P75 & Desvio-Padrão & Mínimo & Máximo & Obs. \\
\hline Propensão & $-0,81$ & $-0,49$ & 0,63 & 1,00 & $-0,81$ & 2,50 & 45 \\
Poder & $-0,31$ & $-0,31$ & $-0,10$ & 1,00 & $-1,25$ & 5,17 & 45 \\
Sensibilidade & $-0,79$ & $-0,07$ & 0,63 & 1,00 & $-1,32$ & 2,05 & 45 \\
Ansiedade & $-0,74$ & $-0,34$ & 0,51 & 1,00 & $-1,12$ & 2,98 & 45 \\
Atitude & $-0,65$ & $-0,47$ & 0,62 & 1,00 & $-1,73$ & 2,63 & 45 \\
Renda & 8,29 & 8,69 & 9,55 & 1,05 & 6,91 & 11,92 & 38 \\
Escolaridade & 1,00 & 1,00 & 1,00 & 0,81 & 1 & 4 & 45 \\
\hline
\end{tabular}

Fonte: Dados da pesquisa (2019).

Os resultados da análise descritiva das variáveis de interesse desta pesquisa evidenciam, ao considerar a mediana, que o menor fator foi da variável Propensão ao Endividamento com -0,49. Por outro lado, o maior valor da mediana corresponde a variável de Sensibilidade ao Preço, com -0,07.

$\mathrm{Na}$ análise das variáveis de controle, percebe-se que a mediana da Renda apresentou valor de 8,69. Este valor corresponde a seis salários mínimos (ao considerar o salário mínimo estabelecido pelo Governo Federal em todo o território brasileiro para o ano de 2019). Outra variável de controle utilizada nesta pesquisa compreende ao nível de escolaridade dos respondentes. As evidências apontam que a mediana, assim como o percentil 25 e 75 desta variável é igual a 1 , em que isto demonstra que a maior parte dos jogadores tem nível de escolaridade menor ou igual ao ensino médio completo. Posteriormente a análise descritiva, realizou-se a análise de correlação de Pearson, com a finalidade de analisar a correlação das conforme apresentado Tabela 6.

Tabela 6 - Matriz de correlação de Pearson

\begin{tabular}{|c|c|c|c|c|c|c|c|}
\hline Variáveis & Propensão & Poder & Sensibilidade & Ansiedade & Atitude & Renda & Escolaridade \\
\hline Propensão & 1 & & & & & & \\
\hline Poder & $0,249 *$ & 1 & & & & & \\
\hline Sensibilidade & $-0,024$ & 0,086 & 1 & & & & \\
\hline Ansiedade & $0,353^{* *}$ & 0,181 & 0,226 & 1 & & & \\
\hline Atitude & 0,207 & 0,138 & $0,305^{\star *}$ & $0,447^{\star \star \star}$ & 1 & & \\
\hline Renda & $-0,003$ & $-0,035$ & $-0,115$ & $-0,163$ & 0,078 & 1 & \\
\hline Escolaridade & $-0,214$ & 0,016 & 0,016 & $-0,185$ & $-0,195$ & 0,224 & 1 \\
\hline
\end{tabular}

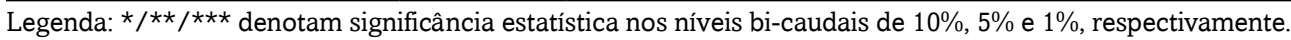

Fonte: Dados da pesquisa (2019)

Os resultados da análise de correlação de Pearson da variável dependente, percebe-se que o maior coeficiente de correlação foi da variável Ansiedade com 0,353 seguido da variável Poder e Prestígio, com 0,249. Este resultado pode indicar que o Poder e Prestígio, assim como, Ansiedade podem estar relacionadas com a Propensão ao Endividamento. Quanto a análise da correlação das variáveis independentes, nota-se que nenhum dos resultados apresenta coeficiente acima de 0,70 (correlação forte). De acordo com Gujarati (2009) e Fávero e Belfiore (2017), não há indícios de multicolinearidade para o modelo multivariado. Outro teste realizado confere ao teste de VIF, em que todas as variáveis apresentaram resultado inferior a 5 , em que isto demonstra que não há indícios de multicolinearidade, como sugerido por Wooldridge (2010) e Fávero e Belfiori (2015). 
Tabela 7 - Modelos multivariados da Propensão ao Endividamento

\begin{tabular}{|c|c|c|c|c|c|}
\hline \multirow{5}{*}{$\begin{array}{l}\text { Variáveis } \\
\text { Independentes }\end{array}$} & \multicolumn{5}{|c|}{ Quantil } \\
\hline & Perfil 1 & Perfil 2 & Perfil 3 & Perfil 4 & Perfil 5 \\
\hline & 0,10 & 0,25 & 0,50 & 0,75 & 0,90 \\
\hline & Coef & Coef & Coef & Coef & Coef \\
\hline & (Est T) & (Est T) & (Est T) & (Est T) & (Est T) \\
\hline Poder & $\begin{array}{l}0,300 \\
(2,88)^{\star \star \star}\end{array}$ & $\begin{array}{l}0,191 \\
(1,87)^{\star}\end{array}$ & $\begin{array}{l}0,176 \\
(1,39)\end{array}$ & $\begin{array}{l}0,012 \\
(0,02)\end{array}$ & $\begin{array}{l}-0,143 \\
(-0,31)\end{array}$ \\
\hline Sensibilidade & $\begin{array}{l}-0,068 \\
(-0,64)\end{array}$ & $\begin{array}{l}-0,088 \\
(-0,74)\end{array}$ & $\begin{array}{l}-0,099 \\
(-0,52)\end{array}$ & $\begin{array}{l}0,112 \\
(0,31)\end{array}$ & $\begin{array}{l}-0,306 \\
(-0,74)\end{array}$ \\
\hline Ansiedade & $\begin{array}{l}-0,001 \\
(-0,01)\end{array}$ & $\begin{array}{l}0,091 \\
(0,55)\end{array}$ & $\begin{array}{l}0,134 \\
(0,45)\end{array}$ & $\begin{array}{l}0,632 \\
(1,56)\end{array}$ & $\begin{array}{l}0,894 \\
(2,35)^{\star \star}\end{array}$ \\
\hline Atitude & $\begin{array}{l}0,108 \\
(0,64)\end{array}$ & $\begin{array}{l}0,338 \\
(1,92)^{\star}\end{array}$ & $\begin{array}{l}0,268 \\
(0,69)\end{array}$ & $\begin{array}{l}-0,334 \\
(-0,70)\end{array}$ & $\begin{array}{l}-0,088 \\
(-0,21)\end{array}$ \\
\hline Renda & $\begin{array}{l}0,010 \\
(0,12)\end{array}$ & $\begin{array}{l}-0,040 \\
(-0,32)\end{array}$ & $\begin{array}{l}-0,037 \\
(-0,16)\end{array}$ & $\begin{array}{l}0,352 \\
(0,86)\end{array}$ & $\begin{array}{l}0,675 \\
(1,56)\end{array}$ \\
\hline Escolaridade & $\begin{array}{l}-0,161 \\
(-0,75)\end{array}$ & $\begin{array}{l}-0,014 \\
(-0,19)\end{array}$ & $\begin{array}{l}-0,085 \\
(-0,41)\end{array}$ & $\begin{array}{l}-0,684 \\
(-1,78)^{\star}\end{array}$ & $\begin{array}{l}-0,491 \\
(-0,92)\end{array}$ \\
\hline Constante & $\begin{array}{l}-0,638 \\
(-0,85)\end{array}$ & $\begin{array}{l}-0,130 \\
(-0,13)\end{array}$ & $\begin{array}{l}0,077 \\
(0,04)\end{array}$ & $\begin{array}{l}-1,455 \\
(-0,45)\end{array}$ & $\begin{array}{l}-4,083 \\
(-1,11)\end{array}$ \\
\hline R2 & 0,042 & 0,147 & 0,257 & 0,217 & 0,312 \\
\hline Observações & & & 38 & & \\
\hline
\end{tabular}

Legenda: Perfil 1 (Quantil 0,10): Jogadores com baixíssima propensão a se endividar; Perfil 2 (Quantil 0,25): Jogadores com baixa propensão a se endividar; Perfil 3 (Quantil 0,50): Jogadores propensos ao endividamento; Perfil 4 (Quantil 0,75): Jogadores com elevada propensão a se endividar e Perfil 5 (Quantil 0,90): Jogadores com elevadíssima propensão a se endividar. * significância ao nível de 10\%; **significância ao nível de $5 \%$; ** significância ao nível de $1 \%$. As regressões foram estimadas a partir do modelo em quantis $(0,10$; $0,25 ; 0,50 ; 0,75$ e 0,90$)$, em que foram obtidos a partir das seguintes equações: PROPENSÃOi $=\beta_{0}+\beta_{1}$ PODER $+\beta_{2}$ SENSIBILIDADE + $\beta_{3}$ ANSIEDADE $_{i}+\beta_{4}$ ATITUDE $_{i}+\beta_{5}$ RENDA $_{i}+\beta_{6}$ ESCOLARIDADE $_{i}+\varepsilon_{i}$

Fonte: Dados da pesquisa (2019)

Na Tabela 7, demonstra-se que o exercício do poder e prestígio está positivamente relacionado com a propensão ao endividamento dos jogadores do Perfil 1 e 2. Com isso, confirma-se a H1, além de estar conforme a literatura como apresentado por Roberts e Jones (2001). Assim, constata-se que os jogadores com baixíssima e baixa propensão ao endividamento são mais suscetíveis a se endividarem a partir do aumento do exercício do poder e prestígio. Contudo, ressalta-se que isso não ocorre para os jogadores que são propensos ao endividamento ou com elevada ou elevadíssima propensão a se endividar (Perfil 3, 4 e 5, respectivamente).

$\mathrm{Na}$ análise da sensibilidade ao preço, observa-se que esta variável não apresenta relação com a propensão ao endividamento de nenhum perfil analisado. Evidência que confirma a rejeição da H2, bem como, diferir da literatura sobre o reflexo da sensibilidade ao preço no endividamento, como abordado por Yamauchi e Templer (1982). A partir deste resultado, entende-se que a sensibilidade ao preço não tem impacto na propensão ao endividamento dos jogadores de futebol, o que pode sinalizar que o aumento de gastos extras não se reflete na propensão ao endividamento destes profissionais. Assim, pode comprometer o planejamento financeiro a longo prazo, especialmente, porque conforme Brandão (2001), Amaral et al. (2007) e Aroni et al. (2019) a carreira deste profissional é curta.

Outro achado corresponde ao reflexo positivo da ansiedade na propensão ao endividamento apenas para os jogadores do Perfil 5. Desta forma, confirma-se a H3, assim como, verificar que este resultado vai ao encontro das evidências apresentadas por Roberts e Jones (2001). A partir disto, verifica-se que os jogadores com elevadíssima propensão a se endividar são mais sensíveis ao comportamento de ansiedade. Diferentemente, constata-se que os jogadores que pertencem aos demais perfis (Perfil 1, 2, 3 e 4) não tem sua propensão ao endividamento sensível a ansiedade. 
A atitude com cartão de crédito está positivamente relacionada com a propensão ao endividamento dos jogadores do Perfil 2. Assim, confirma-se a H4, além de que esta evidência é consoante com os achados expostos nas investigações de Cheema e Soman, (2006), Lo e Harvey (2011) e Wang et al. (2011). A partir deste resultado, nota-se que a atitude com o cartão de crédito aumenta a propensão ao endividamento dos jogadores que tem baixa propensão a se endividar. Os demais perfis, especialmente os que apresentam maior propensão ao endividamento (Perfil 4 e 5 ) não são sensíveis a atitude com cartão de crédito.

Adicionalmente, percebe-se que a escolaridade está negativamente relacionada com a propensão ao endividamento dos jogadores com elevada propensão a se endividar. Por outro lado, destaca-se que esta relação não ocorre para todos perfis de jogadores, na qual pode ser decorrente da predominância dos profissionais com o mesmo nível de escolaridade (ensino médio completo). Adicionalmente, certifica-se que a renda não está relacionada com a propensão ao endividamento. Com isso, o aumento da renda não é um fator que tem reflexo na propensão ao endividamento dos jogadores profissionais de futebol.

Ainda, destaca-se que os modelos multivariados da propensão dos jogadores do Perfil 1 e 2 apresentaram $\mathrm{R}^{2}$ 0,042; 0,147 e 0,257 . O que indica que as variáveis independentes destes modelos explicam 4,2\%; $14,7 \%$ e $25,7 \%$ da variação da propensão de endividamento dos jogadores do Perfil 1, 2 e 3 . Ainda, o $\mathrm{R}^{2}$ do modelo multivariado da propensão ao endividamento dos jogadores do Perfil 4 e 5 é de 0,217 e 0,312. Evidência que demonstra que as variáveis independentes do modelo implicam em $21,7 \%$ e $31,2 \%$ da variação da propensão ao endividamento dos jogadores do Perfil 4 e 5 , respectivamente.

\section{CONSIDERAÇÕES FINAIS}

Diante do exposto, poder e prestígio, atitude com cartão de crédito e ansiedade explicam a propensão ao endividamento dos jogadores profissionais de futebol. Conclui-se que o poder e prestígio dos jogadores profissionais de futebol está positivamente relacionado a propensão ao endividamento. A partir deste achado, o exercício do poder e prestígio aumenta a propensão ao endividamento dos respondentes que possuem baixíssima e baixa propensão a se endividar. Constatou-se que a atitude com cartão de crédito está positivamente relacionada com a baixa propensão ao endividamento. Outro resultado apresenta que a ansiedade dos jogadores profissionais de futebol (com elevadíssima propensão a se endividar) tem relação com o aumento da propensão ao endividamento.

Neste contexto, o estudo apresenta implicações teórico-empíricas concernentes a temática, conforme ponderado por Maseko (2013), Figueira e Pereira, (2014), Surujlal (2016), Gamble, Garling e Michaelsen (2019) e Santos et al., (2019). Quanto aos constructos, demonstrou-se aplicabilidade e adaptação em uma amostra específica, o que serve como um avanço. Na implicação voltada ao campo, apresentaram-se fatores que são explicativos a propensão ao endividamento dos jogadores profissionais de futebol.

Em âmbito prático, o apoio do setor de recursos humanos dos clubes de futebol, conselheiros, família, como também cursos, é fundamental para lidar com as finanças destes jogadores. Destaca-se que a sensação do poder e prestígio pode ser preditor para o endividamento e que alguns jogadores gozam desta posição. Isso requer equilíbrio e consciência para não gastar em excesso. Deve-se, também, atentar a ansiedade, uma vez conduzir para o endividamento. O resultado do estudo discute da necessidade de gestão das finanças ao longo da carreira ao saber que a atividade finda em período curto, o que este profissional deve pensar de forma contínua no seu pós-carreira. Recomenda-se aos jogadores que procurem os serviços de um profissional contábil como consultor financeiro e que busquem um programa intensivo para se educar sobre orçamento gasto com sabedoria, administrar um negócio, entre outros. Isso permitirá que os jogadores de futebol planejem uma situação financeira sustentável em sua aposentadoria.

Os resultados da investigação requerem parcimônia em vista de suas limitações, em especial o número de respondentes, o que impossibilita resultados mais contundentes e generalizações. Vale salientar que esta pesquisa é embrionária, o que implica na necessidade da realização de mais estudos o que resulta em amadurecimento e aperfeiçoamento do conhecimento científico sobre a realidade financeira destes profissionais. Outros fatores poderão explicar a propensão ao endividamento e que deve incentivar e ser objeto de novas investigações. Contudo, a contribuição desta investigação é gerar reflexões na comunidade acadêmica e profissional, especialmente sobre o papel da educação financeira para que estes profissionais almejem conforto financeiro após a sua carreira, seja em sua aposentadoria ou na mudança de carreira.

\section{AGRADECIMENTOS}

O presente trabalho foi realizado com apoio da Coordenação de Aperfeiçoamento de Pessoal de Nível Superior Brasil (CAPES) - Código de Financiamento 001. 


\section{REFERÊNCIAS}

Agresta, M. C., Brandão, M. R. F., \& Neto, T. L. D. B. (2009). Impacto do término de carreira esportiva na situação econômica e profissional de jogadores de futebol profissional. Revista Brasileira de Ciência e Movimento, 16(1), 31-38.

Amaral, P. R. T., Thiengo, C. R., \& OLIVEIRA, F. I. D. S. (2007). Os motivos que levaram jogadores de futebol amador a abandonarem a carreira de jogador profissional. Revista Digital-Buenos Aires-Ano.

Aroni, A., Bagni, G., Bocchio, G. L., \& Machado, A. A. (2019). Estresse da iniciação esportiva até profissionalização: uma análise exploratória da trajetória de atletas profissionais de Futebol. RBFF-Revista Brasileira de Futsal e Futebol, 11(43), 263-272.

Bernthal, M. J., Crockett, D., \& Rose, R. L. (2005). Credit cards as lifestyle facilitators. Journal of Consumer Research, 32(1), 130-145.

Bourke, A. (2003). The dream of being a professional soccer player: Insights on career development options of young Irish players. Journal of sport and social issues, 27(4), 399-419.

Brandão, M. R. F. (2000). Fatores de stress em jogadores de futebol profissional. Tese (Doutorado em Educação Física) - Programa de Pós-Graduação em Educação Física da Universidade de Campinas, Campinas.

Brown, S., Taylor, K., \& Price, S. W. (2005). Debt and distress: Evaluating the psychological cost of credit. Journal of Economic Psychology, 26(5), 642-663.

CBF. Confederação Brasileira de Futebol. (2016). Raio-x do futebol: salário dos jogadores. Recuperado de https://www.cbf.com. br/a-cbf/informes/index/raio-x-do-futebol-salario-dos-jogadores.

Cheema, A., \& Soman, D. (2006). Malleable mental accounting: The effect of flexibility on the justification of attractive spending and consumption decisions. Journal of Consumer Psychology, 16(1), 33-44.

CNC. Confederação Nacional do Comércio de Bens, Serviços e Turismo. (2016). Pesquisa nacional de endividamento e inadimplência do consumidor (Peic). Recuperado de: http://www.cnc.org.br/central-doconhecimento/pesquisas/pesquisa-nacional-de-endividamento-e-inadimplencia-do-consumidor.

Damo, A. S. (2005). Do dom à profissão: uma etnografia do futebol de espetáculo a partir da formação de jogadores no Brasil e na França. Tese (Doutorado em Antropologia Social) - Programa de Pós-Graduação em Antropologia Social da Universidade Federal do Rio Grande do Sul, Porto Alegre.

Eastwood, D. (1975). Consumer credit and the theory of consumer behavior. Journal of Behavioral Economics, 4(1), 39-105.

Erasmus, A. C., \& Lebani, K. (2008). Store cards: is it a matter of convenience or is the facility used to sustain lavish consumption?. International journal of consumer studies, 32(3), 211-221.

Fávero, L. P., \& Belfiore, P. (2017). Manual de análise de dados: estatística e modelagem multivariada com Excel®, SPSS® e Stata®. Elsevier Brasil.

Feinberg, R. A. (1986). Credit cards as spending facilitating stimuli: A conditioning interpretation. Journal of consumer research, 13(3), 348-356.

Ferreira, R. (2006). Como planejar, organizar e controlar seu dinheiro: manual de finanças pessoais. São Paulo: IOB Thomson.

Ferreira, S. E. N. (2013). Uma análise comportamental aos inquéritos sobre endividamento dos particulares em Portugal. (Dissertação de Mestrado). Faculdade de Economia da Universidade de Porto. Portugal, Porto, $155 \mathrm{f}$.

Figueira, R. F., \& Pereira, R. D. C. D. F. (2014). Devo, Não Nego, Pago Quando Puder: uma Análise dos Antecedentes do Endividamento do Consumidor. Revista Brasileira de Marketing, 13(5), 124-138.

Fleishman-Hillard (2011). SAFPU and Liberty bring Financial Freedom to the Game. http://www.insurancegateway.co.za/LifeProfessionals/PressRoom/ViewPress/Irn=5367\&URL=SAFPU+and+Liberty+bring+Financial+Freedom+to+the+Game+1.Accessed on 13/04/2019.

Frade, C., Lopes, C., Nogueira, C., Magalhaes, S., Brinca, P., \& Marques, M. M. L. (2003). Desemprego e sobre endividamento dos consumidores: contornos de uma "ligaçao perigosa". Relatório do Observatório do Endividamento dos Consumidores.

Gamble, A., Gärling, T., \& Michaelsen, P. (2019). Young Adults’ Attitudes Toward Borrowing. In Indebtedness in Early Adulthood (pp. 65-87). Palgrave Macmillan, Cham.

Gathergood, J. (2012). Self-control, financial literacy and consumer over-indebtedness. Journal of economic psychology, 33(3), 590-602.

Gujarati, D. N. (2009). Basic econometrics. Tata McGraw-Hill Education.

Harnish, R. J., Bridges, K. R., Nataraajan, R., Gump, J. T., \& Carson, A. E. (2018). The impact of money attitudes and global life satisfaction on the maladaptive pursuit of consumption. Psychology \& Marketing, 35(3), 189-196.

Keese, M. (2012). Who feels constrained by high debt burdens? Subjective vs. objective measures of household debt. Journal of Economic Psychology, 33(1), 125-141.

Lachance, M. J. (2012). Young adults' attitudes towards credit. International Journal of Consumer Studies, 36(5), 539-548.

Lavallee, D. (2005). The effect of a life development intervention on sports career transition adjustment. The sport psychologist, 19(2), 193-202.

Lo, H. Y., \& Harvey, N. (2011). Shopping without pain: Compulsive buying and the effects of credit card availability in Europe and the Far East. Journal of Economic Psychology, 32(1), 79-92. 
Mansfield, P. M., \& Pinto, M. B. (2008). Consumer vulnerability and credit card knowledge among developmentally disabled citizens. Journal of consumer affairs, 42(3), 425-438.

Markovich, C. A., \& DeVaney, S. A. (1997). College seniors' personal finance knowledge and practices. Journal of Family and Consumer Sciences, 89(3), 61.

Marques, M. M. L. (Coord.), Vítor Neves, Catarina Frade, Flora Lobo, Paula Pinto e Cristina Cruz (2000) - O endividamento dos consumidores. Coimbra: Almedina.

Maseko, J., \& Surujlal, J. (2011). Retirement planning among South African professional soccer players: a qualitative study of players' perceptions: job satisfaction in sport. African Journal for Physical Health Education, Recreation and Dance, 17(Supplement 2), 157-171.

Maseko, J., \& Surujlal, J. (2013). Financial planning for retirement amongst South African professional soccer players. Global Business and Technology Association. 690-696.

Norum, P. S. (2008). The role of time preference and credit card usage in compulsive buying behaviour. International Journal of Consumer Studies, 32(3), 269-275.

Richers, R. (1984). O enigmático mas indispensável consumidor: teoria e prática. Revista de Administra\&ccdeil; ão da Universidade de São Paulo, 19(3).

Roberts, J. A., \& Jones, E. (2001). Money attitudes, credit card use, and compulsive buying among American college students. Journal of consumer affairs, 35(2), 213-240.

Santos, D. B., Mendes-Da-Silva, W., Norvilitis, J. M., \& da Silva Flores, E. (2019). Credit Card and Financial Well-Being Among Females. In Individual Behaviors and Technologies for Financial Innovations (pp. 97-116). Springer, Cham.

Sevim, N., Temizel, F., \& Sayılır, Ö. (2012). The effects of financial literacy on the borrowing behaviour of T urkish financial consumers. International Journal of Consumer Studies, 36(5), 573-579.

SPC. Serviço de Proteção ao Crédito. (2016). Análise da educação financeira: habilidades. Recuperado de: https://www.spcbrasil. org.br/wpimprensa/wp-content/uploads/2016/04/Analise-Educacao-Financeira-Habilidades1.pdf.

Surujlal, J. (2016). Influence of organizational support on retirement planning and financial management of professional soccer players. Polish Journal of Management Studies, 13(2), 164-174.

Tokunaga, H. (1993). The use and abuse of consumer credit: Application of psychological theory and research. Journal of economic psychology, 14(2), 285-316.

Vickers, E. (2014). Life after sport: Depression in the retired athlete. The Sport in Mind. http://believeperform.com/wellbeing/ life-after-sport-depression-in-retired-athletes/, Accessed on: 29.05.2019.

Wang, J., \& Xiao, J. J. (2009). Buying behavior, social support and credit card indebtedness of college students. International Journal of Consumer Studies, 33(1), 2-10.

Wang, L., Lu, W., \& Malhotra, N. K. (2011). Demographics, attitude, personality and credit card features correlate with credit card debt: A view from China. Journal of economic psychology, 32(1), 179-193.

Wang, L., Lv, W., \& Jiang, L. (2011). The impact of attitude variables on the credit debt behavior. Nankai Business Review International, 2(2), 120-139.

Wickramasinghe, V., \& Gurugamage, A. (2009). Consumer credit card ownership and usage practices: empirical evidence from Sri Lanka. International Journal of Consumer Studies, 33(4), 436-447.

Wooldridge, J. M. (2015). Introductory econometrics: A modern approach. Nelson Education.

Xiao, J. J., Tang, C., Serido, J., \& Shim, S. (2011). Antecedents and consequences of risky credit behavior among college students: Application and extension of the theory of planned behavior. Journal of Public Policy \& Marketing, 30(2), 239-245.

Yamauchi, K. T., \& Templer, D. J. (1982). The development of a money attitude scale. Journal of personality assessment, 46(5), 522-528. 